the $S$ is required to perform the task exactly as demonstrated, it does better than if the task varied from the one demonstrated. Following is something that should be controlled in the observational learning experiment. It probably plays less of a role in studies with a Skinner box or a shuttlebox. but in a study with a maze, as this one, it is important. One would not want to attribute more rapid learning of a discrimination task to observational learning if all the $\mathrm{S}$ was doing was following the demonstrator. Two of the Ss of Group 6 were run without the demonstrator after they had reached criterion. They continued to go to the striped panel even though the demonstrator had not modeled the task, thus suggesting that they did learn the discrimination, in addition to learning to follow the demonstrator.

\section{REFERENCES}

BANDURA, A. Social learning through imitation. In M. R. Jones (Ed.), Nebrasko symposium on motivation: 1962 . Lincoln: University of Nebraska Press, 1962. Pp. 211-269.

BANDURA. A. Vicarious processes: A case of no-trial learning. In $\mathrm{L}$. Berkowitz (Ed.), Advances in experimental social psychology'. New York: Academic Press, 1965a. Pp. 1-55

BA NDURA, A. Behavior modification through modeling procedures. In L. Krasner and L. P. Ullman (Eds.), Research in behavior modification. New York: Holt, Rinehart, \& Winston, $1965 \mathrm{~b}$. Pp. 310-340.

CORSON, J. A. Observational learning of a lever pressing response. Psychonomic Science, $1967,7,197-198$.

DIXON, W. \& MASSEY, F, J Introduction to statistical analysis. New York: McGraw-Hill, 1957.

HERBERT, M. J., \& HARSH, C. M. Obersvational learning by cats. Journal of Comparative Psychology, 1944, 37. 81.95.

JOHNS, E. R., CHESLER, P., BARTLETT, F., \& VICTOR, I. Observation learning in cats. Science, 1968, 159, 1489-1491.

KANFER, F. H. Self-regulation. Paper presented at the Ninth Annual Institute for Research in Clinical Psychology, "Behavior Modification in Clinical Psychology," at the University of Kansas, 1967.

KINNAMAN, A, J, Mental life of two Macacus rhesus monkeys in captivity. American Journal of Psychology, 1902 $13,98-149$.

MILLER, N. E., \& DOLLARD, J. Social learning and imitation. New Haven: Yale University Press, 1941.

THORNKIDE, E. L. Animal intelligence. Psychological Review Monograph Supplement, 1898, 2, 1-109.

YERKES, R. M. Suggestibility in chimpanzees. Journal of Social Psychology, 1934,5,272-282.

\title{
The effect of food deprivation on shock elicited aggression in rats
}

\author{
D. D. CAHOON*, RAY M. CROSBY, SANDRA DUNN, M. S. HERRIN, \\ CHARLES C. HILL, and MARCIA McGINNIS \\ Auburn University, Auburn, Ala. 36830
}

Aggressive responses were tabulated for albino rats under conditions of shock stimulation only, food deprivation only, and shock plus food deprivation Results indicated that while deprivation alone did not result in aggression as defined in the experiment, deprivation plus shock elicited more aggression than shock alone. Further, the number of aggressive responses was found to vary positively with amount of deprivation.

A number of experiments have demonstrated that aversive stimulation can elicit aggression in a variety of species, and that the effectiveness of this stimulation is qualified by such variables as the intensity, duration, and mode of punishment (e.g., Ulrich \& Azrin, 1962; Hutchison, Azrin, \& Renfrew, 1968). Few studies, however, have attempted to relate aggression to the degree of deprivation obtaining during the experiment. Azrin, Hutchison, \& Hake (1966)

* Requests for reprints should be sent to D. D. Cahoon, Department of Psychology, Auburn University, Auburn, Alabama 36830 . observed that attack elicited in pigeons by an extinction schedule was reduced by satiation. Davis (1933) reported that rats housed alone, if deprived of food, exhibited attack behavior toward "intruder" rats placed in the home cage when food was present. An experiment by Franchina (1966) suggested that deprivation and aversive stimulation may summate under some conditions. When 0 and $23^{1 / 2} \mathrm{~h}$ of food deprivation were combined with 40 and $70-\mathrm{V}$ shock during an escape trial, performance was directly related to both level of deprivation and shock intensity. On the other hand, Griffiths (1962) demonstrated that 12 - and 24-h food-deprived rats tolerated greater shock intensity than did nondeprived Ss, with 24-h deprivation being related to greater tolerance than the 12 -h period.

The present experiment was designed to determine if food deprivation would increase the number of aggressive responses elicited by electric shock in the albino rat.

\section{SUBJECTS}

Nine experimentally naive male Sprague-Dawley-derived rats from the Auburn University colony were used as Ss. All Ss were approximately 90 days old at the initiation of the experiment.

\section{APPARATUS}

A rat-restraining apparatus with target switch was designed similar to that described by Azrin, Rubin, \& Hutchison (1968). The restraining chamber consisted of a $22 \times 6 \times 6 \mathrm{~cm}$ opaque tube that would not permit the rat to twist or turn when in position. The tube was attached to a flat board and held in place by aluminum braces. A brass tail-restraining rod was fastened to the board at one end of the Plexiglas tube. When a rat was placed in the apparatus a sliding panel with an opening at the base to accommodate the 'Ss' tail enclosed the rear of the tube. This prevented the $S$ from backing out of the chamber but allowed his tail to extend outside of the box. Adhesive tape was used to secure the rat's tail to the restraining rod.

The target was constructed to measure aggression as defined by biting and pulling behavior. This apparatus consisted of a $1 / 2-\mathrm{cm}$-diam doubled brass rod, approximately $7 \mathrm{~cm}$ long, and covered with easily replaceable white adhesive tape at the end nearer the rat. The target was movable and thus could be adjusted with respect to distance from the S's mouth. Biting and pulling the target rod $1 \mathrm{~cm}$ toward the $S$ closed a switch and transmitted an impulse to the recording apparatus.

Shock was delivered to the tail by a constant-current source through external clip electrodes attached to the base and tip of the tail. The rat's tail was kept moist with water during all of the experimental sessions to ensure an adequate electrical contact. Standard programming equipment was used to record the total number of responses for each experimental session and to present shock of a specific duration and intensity at fixed intervals.

\section{PROCEDURE}

Prior to the experiment all Ss were placed in the apparatus for $10 \mathrm{~min}$ to allow for adaptation to the chamber and to measure pretest aggressiveness. Only one rat bit the target during this 
Table 1

Number of Biting Responses Over Sessions for Shocked Nondeprived Rats (Group S) and for Shocked Food-Deprived Rats (Group D+S). Ss who were food deprived but not shocked (Group D) exhibited no biting responses and are not included in the table.

\begin{tabular}{|c|c|c|c|c|c|c|c|c|}
\hline \multirow[b]{2}{*}{ Sessions } & \multicolumn{4}{|c|}{$\mathbf{S}$} & \multicolumn{4}{|c|}{$\mathrm{D}+\mathrm{S}$} \\
\hline & S 1 & S 2 & S 3 & Total & S 1 & S 2 & S 3 & Total \\
\hline 1 & 44 & 18 & 156 & 218 & 107 & 74 & 67 & 248 \\
\hline 2 & 17 & 12 & 81 & 110 & 0 & 75 & 130 & 205 \\
\hline 3 & 23 & 7 & 80 & 110 & 40 & 157 & 71 & 268 \\
\hline \multirow[t]{2}{*}{4} & 27 & 26 & 29 & 82 & 71 & 84 & 40 & 195 \\
\hline & & $\bar{x}=43$ & & 520 & & $\bar{x}=76$ & & 916 \\
\hline
\end{tabular}

phase, and he was replaced with a $\mathrm{S}$ that did not bite the target. The rats were then divided randomly into three groups of three Ss each and marked for identification. The groups were labeled "shock only" (S), "deprivation only" (D), and "deprivation plus shock" $(D+S)$. Prior to the first experimental session, Groups $\mathrm{D}$ and $\mathrm{D}+\mathrm{S}$ were deprived of food for $24 \mathrm{~h}$.

For four sessions, $24 \mathrm{~h}$ apart, the Ss were placed individually in the chamber, their tails taped to the tail-restraining rod, and the electrodes attached. The target was positioned about $1 \mathrm{~cm}$ from the nose of the rat, ensuring that the $S$ would have to stretch slightly to reach the target. During each session the $\mathrm{S}$ was placed in the apparatus for $20 \mathrm{~min}$ and, in the shock group, a 4-mA shock was applied for $.5 \mathrm{sec}$, with a $3-\mathrm{sec}$ intershock interval. The shock stimulus was therefore presented for a total of 400 times during each test period for each rat. Following the session the deprivation groups were free-fed for only $30 \mathrm{~min}$, ensuring an increasing degree of deprivation over sessions. The number of aggressive responses were recorded for all $\mathrm{S}$ during the experiment.

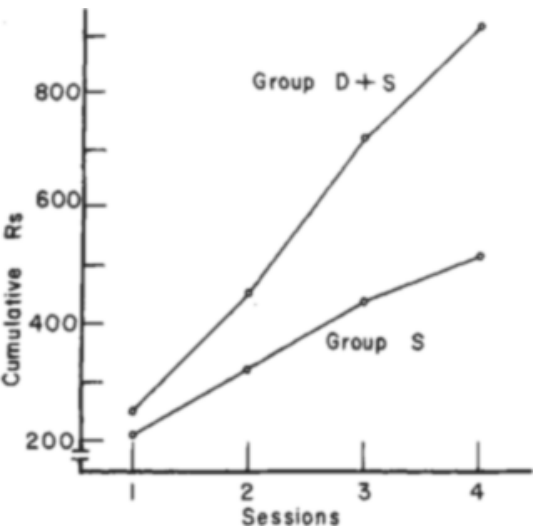

Fig. 1. Cumulative number of responses for Groups S (shock only) and $\mathbf{D}+\mathbf{S}$ (deprivation plus shock) over four 20-min sessions. The Ss in Group D (deprivation only) did not respond during the first two sessions and were not run beyond that point.
Groups

is paired with shock, a higher rate of elicited biting behavior is exhibited than when shock is presented to nondeprived organisms. Further, when Groups S and D $+S$ are compared across sessions, it is found that the degree of difference in aggression increases with successive trials. Therefore, it would appear either that shock-elicited aggression increases with degree of deprivation, or alternatively, that deprivation forestalls the habituation to shock, observed when shock alone is presented.

The great variability among Ss, suggesting the confounding effects of unknown or uncontrolled variables related to aggression, is consistent with other experiments. For example, Azrin, Hutchison, \& Hake (1963), studying paired squirrel monkeys, and Azrin, Hutchison, \& Hake (1966), in work with pigeons, reported large individual differences in attack frequency.

Results of the present experiment also suggest a possible reinterpretation of those studies involving the operant conditioning of aggression (e.g., Azrin \& Hutchison, 1967) and aggression during extinction (e.g., Azrin, Hutchison, \& Hake, 1966). That is, since deprivation is a component in both operant acquisition and most extinction studies, at least some of the biting and attack behavior observed may have been influenced by the deprivation state existing at the time of testing.

statistical analyses were applied to the data. Because of the 0 rate of responding, Group D was excluded from these analyses. An analysis of variance revealed a significant (.05 level) interaction between sessions and treatment for Groups $S$ and $D+S$, suggesting that increased deprivation through the sessions was positively related to amount of aggression. The F-max test for homogeneity of variance indicated significantly greater variability among the $D+S$ Ss (.05 level), probably reflecting the confounding influence of deprivation increase over time, adaptation differences, or other variables inconsistently related to deprivation plus shock.

Considered overall, the results would seem to demonstrate that deprivation alone does not elicit aggressions as measured by biting behavior, but that deprivation when paired with shock is positively related to aggression. Further, the extent of this aggression appears to be a function of the amount of deprivation existing at the time of the test.

\section{DISCUSSION}

As no responding occurred in Group D, it may be concluded that food deprivation within the limits investigated does not, by itself, elicit aggression. However, when deprivation

\section{REFERENCES} pigeons by a fixed-interval schedule of reinforcement. Journal of the Experimental Analysis of Behavior, 1967. 10,395-402.

AZRIN, N. H., HUTCHISON, R. R., \& HAKE, D. F. Pain-induced fighting in the squirrel monkey. Journal of the Experimental Analysis of Behavior, 1963 . 6. 620 .

AZRIN, N. H., HUTCHISON, R. R., \& HAKE, D. F. Extinction-induced aggression. Journal of the Experimental Analysis of Behavior, 1966,9,191-204. AZRIN, N. H., RUBIN, H. B., \& HUTCHISON, R. R. Biting attack by rats in response to aversive shock. Journal of the Experimental Analysis of Behavior. $1968,11,633-639$.

DAVIS, F. C. The measurement of aggressive behavior in laboratory rats Journal of Genetic Psychology, 1933, 43, 213-217.

FRANCHINA, J. J. Combined sources of motivation and escape responding. Psychonomic Science, 1966, 6, 221-222.

GRIFFITHS, W. J., JR. Effects of food and water deprivation on shock tolerance of albino rats. Psychological Reports, 1962, 11, 163-166.

HUTCHISON, R. R. AZRIN, N. H., \& RENFREW, J. W. Effects of shock intensity and duration on the frequency of biting attack by squirrel monkeys. Journal of the Experimental Analysis of Behavior, 1968, 11, 83-88.

ULRICH, A. E., \& AZRIN, N. H. Reflexive fighting in response to aversive stimulation. Journal of the Experimental Analysis of Behavior, $1962,5,511-520$.
AZRIN, N. H., \& HUTCHISON, R. R. Conditioning of the aggressive behavior of 